Article

\title{
Optical Characterization of Alternaria spp. Contaminated Wheat Grain and Its Influence in Early Broilers Nutrition on Oxidative Stress
}

\author{
Nikola Puvača ${ }^{1, *(1)}$, Snežana Tanasković ${ }^{2}\left(\mathbb{D}\right.$, Vojislava Bursić $^{3}$, Aleksandra Petrović $^{3}$, Jordan Merkuri ${ }^{4}$, \\ Tana Shtylla Kika ${ }^{5}$, Dušan Marinković ${ }^{3}$, Gorica Vuković ${ }^{6}$ and Magdalena Cara ${ }^{4}$
}

1 Department of Engineering Management in Biotechnology, Faculty of Economics and Engineering Management in Novi Sad, University Business Academy in Novi Sad, Cvećarska 2, 21000 Novi Sad, Serbia

2 Faculty of Agronomy in Čačak, University of Kragujevac, Cara Dušana 34, 32102 Čačak, Serbia; stanasko@kg.ac.rs

3 Department for Phytomedicine and Environmental Protection, Faculty of Agriculture, University of Novi Sad, Trg Dositeja Obradovića 8, 21000 Novi Sad, Serbia; bursicv@polj.uns.ac.rs (V.B.); aleksandra.petrovic@polj.uns.ac.rs (A.P.); dusan.marinkovic@polj.uns.ac.rs (D.M.)

4 Department of Plant Protection, Faculty of Agriculture and Environment, Agricultural University of Tirana, Koder Kamez, 1029 Tirana, Albania; jordanmerkuri@gmail.com (J.M.); mcara@ubt.edu.al (M.C.)

5 Faculty of Veterinary Medicine, Agricultural University of Albania, Kodër Kamëz, SH1, 1000 Tirana, Albania; tana_kika@hotmail.com

6 Faculty of Agriculture, University of Belgrade, Nemanjina 6, 11080 Belgrade-Zemun, Serbia; goricavukovic@yahoo.com

check for updates

Citation: Puvača, N.; Tanasković, S.; Bursić, V.; Petrović, A.; Merkuri, J.; Shtylla Kika, T.; Marinković, D.; Vuković, G.; Cara, M. Optical Characterization of Alternaria spp. Contaminated Wheat Grain and Its Influence in Early Broilers Nutrition on Oxidative Stress. Sustainability 2021, 13, 4005. https://doi.org/ $10.3390 /$ su13074005

Academic Editor: George K. Symeon

Received: 8 March 2021

Accepted: 1 April 2021

Published: 3 April 2021

Publisher's Note: MDPI stays neutral with regard to jurisdictional claims in published maps and institutional affiliations.

Copyright: (C) 2021 by the authors. Licensee MDPI, Basel, Switzerland. This article is an open access article distributed under the terms and conditions of the Creative Commons Attribution (CC BY) license (https:// creativecommons.org/licenses/by/ $4.0 /)$.
* Correspondence: nikola.puvaca@fimek.edu.rs; Tel.: +381-65-219-1284

Abstract: The aim of this research was the visual characterization and investigating the effects of Alternaria spp. contaminated wheat grains in the starter stage of broilers nutrition on productive parameters and oxidative stress. The research was divided into two phases. Bunches of wheat in postharvest period of year 2020 was collected from a various locality in Serbia and Albania. In the first phase, collected samples were visual characterized by Alternaria spp. presence by color measurement methods. Gained results are conferred in the range of the color properties of grain color properties of Alternaria toxins. Wheat grain samples were significantly different $(p<0.05)$ in terms of all measured color parameters $\left(L^{*}, a^{*}, b^{*}\right)$. Classification of field fungi in analyzed wheat grain samples showed that the significant field fungi were Rhizopus spp., followed by Alternaria spp., and Fusarium spp. In the second phase, biological tests with chickens were carried out during the broiler chickens' dietary starter period in the first 14th days of age. At the beginning of the experiment, a total of 180-day-old Ross 308 strain broilers were equally distributed into three dietary treatments, with four replicates each. Dietary treatments in the experiments were as follows: basal diet without visual contamination of Alternaria spp. with $25 \%$ wheat (A1), a basal diet with visual contamination of Alternaria spp. with $25 \%$ wheat from Serbia (A2), basal diet with visual contamination of Alternaria spp. with $25 \%$ wheat from Albania (A3). The trial with chickens lasted for 14 days. After the first experimental week, wheat infected with Alternaria spp. in treatment A2 and A3 expressed adverse effects. The highest body weight of chickens of $140.40 \mathrm{~g}$ was recorded in broilers on control treatment A1 with statistically significant differences $(p<0.05)$ compared to treatments A2 (137.32 g) and A3 (135.35 g). At the end of the second week of test period, a statistically significant $(p<0.05)$ difference in body weight of broiler chickens could be noticed. The highest body weight of $352.68 \mathrm{~g}$ was recorded in control treatment A1, with statistically significant differences compared to other Alternaria spp. treatments. The lowest body weight of chickens was recorded in treatment A3 (335.93 g). Results of feed consumption and feed conversion ratio showed some numerical differences between treatments but without any statistically significant differences $(p>0.05)$. Alternaria spp. contaminated diet increased glutathione $(\mathrm{GSH})$, glutathione reductase (GR), alanine aminotransferase (ALT), and aspartate aminotransferase (AST) and decreased peroxidase (POD) and superoxide dismutase (SOD) serum levels, respectively. Built on the achieved results, it can be concluded that the wheat contaminated with Alternaria spp. in broilers nutrition negatively affected growth, decreased oxidative protection and interrupted chicken welfare in the first period of life. 
Keywords: Alternaria spp.; mycotoxins; fungi; poultry production; welfare; oxidative stress

\section{Introduction}

Corn and wheat represent the primary energy source in the food animal's daily diet, while wheat has been considered the third most-produced feedstuff globally [1]. In the last ten years, studies and researchers have been struggling with the fungi of the genus Alternaria, which has grown to be the leading cause of wheat grains contamination [2]. The essential characteristics of Alternaria genera is the production of melanin and the hostspecific plant-fungi/toxin interaction [3-5]. In addition, direct melanin emerges an indirect role in virulence, as well [6]. Melanin poses the ability to function as the shield in plant fungi protections versus ecological stress or unfavorable conditions, which gives fungus permanency and endurance. Furthermore, melanin promptly responds with free oxygen radicals, versus the pathogen's infiltration in the plant-host cells $[7,8]$. The blackening of the wheat grain lobes prior to cropping is typical indicator of contamination with Alternaria spp. [9]. At hand there is several forms of discoloration that can alter ordinary wheat (Triticum aestivum L.). In nearly all areas where wheat is cultivated, the black point is usually correlated by Alternaria alternata as a common discoloration of seed [10]. The staining usually appears in the external pericarp and internal grain tissue and could broaden beside its adaxial side. Such kinds of grain color changes differ drastically in frequency and seriousness depending on grain during the maturation. Biotic and abiotic stresses can cause wheat grain color changes, often caused by high humidity and high temperatures [11]. Those kinds of conditions are very favorable for fungi and mycotoxins occurrence in general $[12,13]$. Recently it has been confirmed that high humidity levels might stimulate the sporadic expansion of black point on wheat grain under controlled conditions [14]. A. alternata was the primary cause related to black point occurrence on wheat grain [15]. Likewise, pathogenicity and decrease of quality of wheat grains are influenced by a number of Alternaria spp. the producers of toxic secondary metabolites known as Alternaria mycotoxins [16,17]. Alternaria mycotoxins as alternariol (AOH) [18], tenuazonic acid (TzA) [19], alternariol monomethyl ether (AME) [20], altenuene (ALT) [2], altertoxin I (ATX-I) [21], alterotoxin II (ATX-II) [18], and stemphyltoxin III (STTX-III) [22] could be toxic for animal health [23].

Some of the previous mentioned toxins could cause a serious health damages in animals when ingested, between them, for instance, fetotoxicity and somatic or functional deficiencies in the fetus when the mother is exposed to toxins [23]. A. alternata, as a separate mycotoxin, is mutagenic and clastogenic in various in vitro systems [24]. Moreover, it has been recommended that Alternaria toxins in grains be accountable for gullet pipe cancer [25]. Consequently, because of toxic effects, Alternaria toxins are of concern for public and animal health [26]. The European Commission (EC), and European Food Safety Authority (EFSA) were therefore engaged to give a technical view on the hazards for community and animal wellbeing associated with the occurrence of Alternaria mycotoxins in the commodities for human and animal daily nutrition. Subsequently, A. alternata have been chemically characterized, and incidence in feed was recorded [27]. Nevertheless, more than a few other Alternaria toxins have been classified as well, respectively [28].

Assessment of Alternaria toxins consumption by food animals through daily feeding have been restricted to broilers since poultry have been single one animal race where certain information about mycotoxin toxicity is appropriate for hazard evaluation [29-31]. Given that the incidence of feed data was lacking for the majority of the Alternaria toxins, the exposure assessments have been restricted to $\mathrm{AOH}$ toxin. Estimated lower bound and upper bound introductions to alternariol $(\mathrm{AOH})$ were around $0.003 \mathrm{mg} /$ day and $0.006 \mathrm{mg}$ / day, for chickens and layers, respectively.

Broilers in production conditions are subjected to a variety of stressors [32]. The additional reactive oxygen species (ROS) and reactive nitrogen species (RNS) production 
and oxidative stress are the essential harmful outcomes [33]. In the evolutionary process, antioxidant defense mechanism were built in birds to be able to stay alive in an oxygenated atmosphere [34]. They consist of a dense system of inside integrated antioxidant enzymes, for instance, glutathione (GSH), coenzyme Q (CoQ), and outwardly provided by vitamins, carotenoids, and antioxidants [34]. Furthermore, all antioxidants in the body work together to sustain the best oxidoreduction equilibrium [35]. This equilibrium is a crucial component in supplying the required preconditions for cells indicating, stress adjustment, and homeostasis upkeep [36]. While ROS and RNS are critical signaling molecules, their presence have been rigorously controlled by the antioxidant defense system linked with various transcript components and vitagenes [37]. Physiology shows that change from optimum inner and outer circumstances causes stress [38].

Additionally, a complicated flow of controlling systems is implicated in the stress reaction, causing the metabolic alterations triggering weakened live performance in broilers [39]. When the ROS and RNS construction outstrips the antioxidant defense mechanism ability to neutralize them, oxidative stress arises [38]. That includes polyunsaturated fatty acids (PAFAs), proteins, and DNA [40], take the lead to damaging outcomes in wellbeing, progress, development, and overall animal welfare [41].

Contemplating lucking research results and significant information's on Alternaria mycotoxins and that the biochemical composition of more than a few is identified, this research's precise aim was to visually characterize and investigate the effects of Alternaria spp. contaminated wheat grains in broiler chicken nutrition in the starter stage on productive parameters, oxidative stress, and overall welfare of this species of food animals. Obtained results from this research can serve in the future as the reference material for creating the new up-to-date guidelines on Alternaria toxins in foodstuffs and feedstuffs.

\section{Materials and Methods}

\subsection{Wheat Samples}

Wheat grain samples (Triticum aestivum) were collected in post-harvest time in the season of 2020 from the region of Serbia (Vojvodina) and Albania (Durrës). Obtained samples were collected with the appropriate equipment, such as a probe for stationary grain and a diverter-type mechanical sampler, using a sampling pattern and procedures designed to collect samples from all areas of the lot. The appropriate size of wheat grain between 1.5 and $2.5 \mathrm{~kg}$ sample was taken from a truck with adequate identified and labeled bags. Collected samples were handled in such a way as to maintain representativeness. Samples were stored in a cool and dry place in triple lined paper breathable bags to avoid mold growth and increase of sample moisture level over $14 \%$.

\subsection{Proximate Analyses of Compound Feed for Broilers Chickens}

Compound feed for broiler chickens in each experimental treatment were analyzed for moisture, crude ash, crude protein, crude fat, and crude fiber. All analyses were performed in triplicate. The moisture content was determined according to AOAC (Association of Official Analytical Chemists) [42] Method 934.01. Crude protein content was determined by Kjeldahl method according to the AOAC Method 978.04, crude ash, according to AOAC Method 942.05, crude fat, according to AOAC Method 920.39 and crude fiber according to AOAC Method 978.10 (AOAC, 1998). Concentration of total phosphorus (P) and calcium (Ca) as well as metabolizable energy $(\mathrm{ME})$, was calculated within licenced feed formulation software.

\subsection{Visual Scale Establishing and Color Measurement}

Instrumental methods were used to measure the color of wheat grains. The wheat grain samples color was measured with Minolta Chroma Meter CR-400, and the attachment CR-A50, respectively. The color space defined by the International Commission on Illumination (CIELAB) $L^{*}$ (lightness), $a^{*}$ (red-green), and $b^{*}$ (yellow-blue), and dominant wavelength (DWL) was determined using a D65 light source and the observer angle at 
$2^{\circ}$. The tristimulus values of $L^{*}, a^{*}$ and $b^{*}$ readings were calibrated against a standard white plate $(Y=84.8 ; \mathrm{x}=0.3199 ; \mathrm{y}=0.3377)$. Each wheat ear sample was divided into four subgroups, and the color of one hundred ears from each subgroup (400 ears from one sample) was measured on 5 locations. Samples of wheat grains was divided into 4 subgroups, and 5 repetitions measure were applied in each subgroup (20 repetitions per sample in total) [43].

\subsection{Wheat Grain Infection Confirmation}

Precisely one hundred wheat grains were counted randomly and used in all the treatments. Therefore, wheat grain samples must be cleaned with $0.4 \% \mathrm{NaOCl}$, and washed with clean water for $2 \mathrm{~min}$. After cleaning process samples of wheat was placed on Petri dishes in 4 replicates ( 25 grains/Petri) containing potato dextrose culture medium. Grains were incubated at $25^{\circ} \mathrm{C}$, in total of 7 days, after which concentration of contamination was evaluated. For validation of fungi species from each Petri dish 5 randomly wheat grain was taken out by microscopic inspection after finishing the incubation period [44].

\subsection{In Vivo Experimental Part with Broiler Chickens}

The test with the broilers was conducted in the wake of the EU legislation and tenet of the 3Rs contained by Directive 2010/63/EU, as well with the approval of Ethic Commission for the Protection and Welfare of Experimental Animals EK-I-2020-01. At the beginning of the investigation, a total of 180-day-old Ross 308 strain broilers were equally distributed into three dietary treatments, with four replicates each. Dietary treatments in the experiments were as follows: basal diet without visual contamination of Alternaria spp. with $25 \%$ wheat (A1), a basal diet with visual contamination of Alternaria spp. with $25 \%$ wheat from Serbia (A2), and basal diet with visual contamination of Alternaria spp. with $25 \%$ wheat from Albania (A3). Wheat contamination of Alternaria spp. from control treatment A1 was prepared as $1 / 2$ mixture of wheat samples from both Serbia and Albania. During the test period broilers was given feed and water by will e.g., ad libitum, with regularly monitored and maintained environmental conditions provided by broilers producer. Broilers were kept on the ground bedding system with the pelleted wheat straw. To control the productive results of broilers, body weight, feed consumption, and feed utilization were monitored.

\subsection{Blood Samples Collection and Hemolysate Preparation}

The broiler chickens' blood was collected by the trained veterinarian from the broilers' heart by puncture into heparinized sterile tubes. Blood samples were immediately delivered to the laboratory and centrifugated for $10 \mathrm{~min}$ at $1507 \mathrm{~g}$ and $4{ }^{\circ} \mathrm{C}$. Plasma was removed, following the erythrocytes rinsing in saline three times. The obtained red blood cell pellet was held in same amount of two filtered water and vortexed afterward. Following incubation for $60 \mathrm{~min}$ at $25^{\circ} \mathrm{C}$, the hemolysate was centrifugated during fifteen minutes at $1507 \mathrm{~g}$, after which obtained buoyant was gathered for additional examination [45].

\subsection{Determination of Glutathione and Enzymatic Determination}

To determine glutathione (GSH) concentration, proteins from hemolysates were divided by increasing half amount of $10 \%$ sulfosalicylic acid and centrifugated at $3075 \mathrm{~g}$, for five minutes, at $4{ }^{\circ} \mathrm{C}$. The buoyant was deposited at $4{ }^{\circ} \mathrm{C}$, and GSH was determined the next day. The GSH concentration in the blood hemolysate was determined from the quantity of sulfhydryl residues [45].

Superoxide dismutase (SOD) activity was determined by the spectrophotometric method based on the inhibition of adrenaline reduction to adrenochrome at $\mathrm{pH} 10.2$ [45]. The activity of glutathione reductase (GR) was determined from the rate of nicotinamide adenine dinucleotide phosphate (NADPH) oxidation measured at the absorbance at $340 \mathrm{~nm}$ [46]. The concentration of lipid peroxides (LPx) was determined by the thiobarbituric acid (TBA) assessment [47]. The oxidation of cellular membrane lipids was measured through the reaction of lipid peroxides with TBA [47]. The determination of 
peroxidase (POD) activity was based on the catalytic oxidation of guayacol by $\mathrm{H}_{2} \mathrm{O}_{2}$ as an electron acceptor [45]. The reaction of xanthine oxidation of uric acid was used for the determination of xanthine oxidase (XOD) activity. Spectrophotometric measurement was performed in $0.1 \mathrm{mmol} / \mathrm{dm}^{3}$ phosphate buffer at $\mathrm{pH} 7.5$, at the absorbance at $295 \mathrm{~nm}$ [45].

\subsection{Serum Biochemical Analyses}

The serum activities of aspartate aminotransferase (AST) and alanine aminotransferase (ALT) were determined in serum samples. Analysis of the serum samples was measured by an automatic biochemistry analyzer (Beckman Synchron CX4 PRO, Fullerton, CA, USA) [48].

\subsection{Statistical Analyses of Data}

The data acquired in the conducted examination were evaluated by one-way analysis of variance (ANOVA) using the software package Statistica 13. Once the analysis of variance exhibited statistical significance, Duncan's MRT was employed. A significant difference was registered at $p<0.05$.

\section{Results and Discussion}

Results of proximate analysis of compound feed used in daily nutrition of broiler chickens during the experiment are presented in Table 1.

Table 1. Proximate composition and diet ingredients of compound feed, $\%$.

\begin{tabular}{cccc}
\hline Nutrients & \multicolumn{3}{c}{ Treatments } \\
\cline { 2 - 4 } & A1-Control & A2-Serbia & A3-Albania \\
\hline Dry matter & 89.6 & 89.5 & 89.6 \\
Moisture & 10.4 & 10.5 & 10.4 \\
Crude protein & 22.0 & 22.1 & 22.1 \\
Crude fat & 5.1 & 5.0 & 5.2 \\
Crude fiber & 3.5 & 3.4 & 3.5 \\
Crude ash & 6.3 & 6.4 & 6.2 \\
Ca & 1.0 & 1.1 & 0.9 \\
P & 0.8 & 0.8 & 0.8 \\
Metabolizable Energy, MJ/kg * & 12.5 & 12.5 & 12.5 \\
\hline Diet ingredients & & & \\
Corn & 35.4 & 35.6 & 35.5 \\
Wheat & 25.0 & 25.0 & 25.0 \\
Soybean meal & 19.5 & 19.5 & 2.0 \\
Sunflower meal & 2.0 & 2.0 & 8.5 \\
Soy protein isolate & 8.8 & 8.6 & 2.0 \\
Corn gluten & 2.0 & 2.0 & 1.5 \\
Yeast & 1.5 & 1.5 & 1.8 \\
Limestone & 1.8 & 1.8 & 4.0 \\
Premix & 4.0 & 4.0 &
\end{tabular}

*Values were calculated.

Gained results are conferred in the range of the color properties of grain color properties of Alternaria. Gained results are conferred in the range of the color properties of Alternaria spp. contaminated wheat grains [49]. Wheat grain samples were significantly different $(p<0.05)$ in terms of all measured color parameters $\left(L^{*}, a^{*}, b^{*}\right)$. Control wheat grain (A1) samples were significantly different in terms of lightness and dominant wavelength, compared to wheat grain samples (A2) and (A3), which have shown significant difference $(p<0.05)$ compared to A1, but without any statistically significant difference $(p>0.05)$ between themselves, nevertheless numerical differences (Figure 1), respectively. 


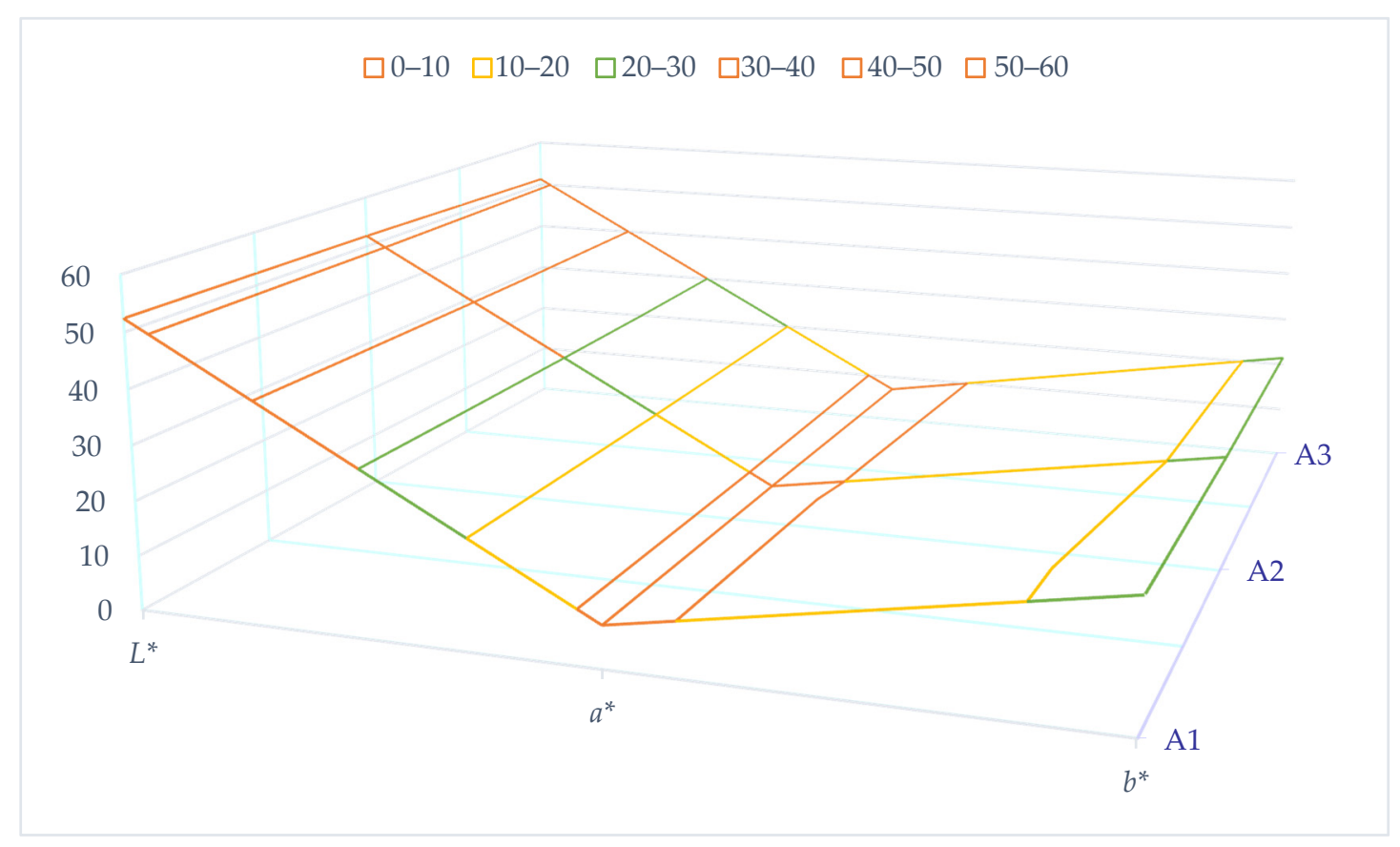

Figure 1. Color parameters of different samples of wheat grains. ${ }^{\mathrm{A} 1}$ - wheat grain without visual contamination of Alternaria spp.; ${ }^{\mathrm{A} 2}$ — wheat grain with visual contamination of Alternaria spp. (Serbia); ${ }^{3}$ — wheat grain with visual contamination of Alternaria spp. (Albania); ${ }^{L^{*}}$-lightness; ${ }^{a^{*}}$-red/green value; ${ }^{b^{*}}$-blue/yellow value.

The results presented in Figure 1 show that all wheat grain samples belong to the different groups by dominant wavelength values. Contemplating all stated, it can be concluded that infection entered the grain in a higher amount in some wheat samples (A2 and A3). Simultaneously, there were samples without visible infection and color changes on the grain (A1). Wheat grain samples without visible dark spots were commonly described by higher lightness and more prominent yellow tones [50].

All wheat grain samples collected from the field and previously instrumentally analyzed were disinfected with $0.4 \% \mathrm{NaOCl}$ and placed for incubation (Section 2.4) for seven days. Results of fungi genera confirmation were carried out by microscopic examination, and the results have been shown in Table 2.

Table 2. Incidence of some genera of fungi in wheat grain samples, $\%$.

\begin{tabular}{ccccc}
\hline \multirow{2}{*}{ Treatment/Sample } & \multicolumn{3}{c}{ Fungi spp. } & Other Fungi spp. \\
\cline { 2 - 5 } & Alternaria & Rhizopus & Fusarium & Not Identified \\
\hline A1-Control & $25.2^{\mathrm{b}}$ & $72.2^{\mathrm{a}}$ & $1.0^{\mathrm{b}}$ & 1.6 \\
A2-Serbia & $37.9^{\mathrm{a}}$ & $48.3^{\mathrm{b}}$ & $3.5^{\mathrm{a}}$ & 10.3 \\
A3-Albania & $39.2^{\mathrm{a}}$ & $46.6^{\mathrm{b}}$ & $3.9^{\mathrm{a}}$ & 10.3 \\
p-value & 0.023 & 0.016 & 0.003 & \\
\hline
\end{tabular}

Values in the same row marked with the different letters are significantly different at the significance level of $p<0.05$.

Classification of field fungi in analyzed wheat grain samples showed that the significant field fungi were Rhizopus spp., followed by Alternaria spp., and Fusarium spp. The ratio of contamination of wheat grain samples by Alternaria spp. was the highest in A3 samples without significant difference $(p>0.05)$ compared to A2, as previously stated. Differences in percentages between $\mathrm{A} 2$ and $\mathrm{A} 3$ could be explained by the fact that Alternaria spp. produce melanin pigments of dark color, which can cause the differentiation in determination with instrumental measurement, respectively. Due to fungi growth in the field even at low temperatures, they are also responsible for spoilage of commodities during refrigerated transport and storage. Several Alternaria species are known producers of toxic 
secondary metabolites known as Alternaria mycotoxins [23]. A. alternata produces several mycotoxins. TeA is harmful to several animal species, e.g., mice, chickens, and dogs [23]. Many Alternaria metabolites have been reported to occur naturally in cereals [5,12]. Alternariol, alternariol monomethyl ether, and tenuazonic acid were frequently detected in sorghum, wheat, and edible oils [23]. Xu et al. [51] have reported the importance and danger of exposure to Alternaria toxins from grain and grain-based products because of its relation to human esophageal cancer in China. In their study, a total of 370 freshly harvested wheat grain samples were analyzed for the four Alternaria toxins TeA, TEN, $\mathrm{AOH}$, and AME. Field contaminated samples (95\%) of the wheat grains were positive for more than one type of Alternaria toxins [51]. Li and Yoshizawa [52] reported the first report of the natural occurrence of Alternaria mycotoxins in Chinese wheat. Their wheat grains were significantly infested by Alternaria species, mainly A. alternata, with a median infection rate of $87.3 \%$. The grains with low quality which is acceptable in some cases was researched in post-harvest period to investigate if the Alternaria or Fusarium influenced in adverse quality of the grains [53]. The distribution of Alternaria and Fusarium spp. they were varied significantly in samples of reduced rate compared with acceptable samples. The results of Kosiak et al. [53] revealed a negative interaction between F. graminearum and Alternaria spp. as well as between F. graminearum and another Fusarium spp. Fusarium and Alternaria fungi naturally occurring on the ears and the formation of their mycotoxins in the ripe grains. Müller et al. [9] investigated the fluorescent pseudomonads colonizing wheat ears, which have a high antagonistic potential against phytopathogenic fungi. Unfortunately, the results of their findings indicate that extensive biological management of mycotoxin development by naturally arising pseudomonads with incompatible activity is very doubtful [9].

Based on the gained results in the second phase of the experiment with the live broiler chickens, after the first experimental week, it could be noticed that the addition of wheat infected with Alternaria spp. in the amount of $25 \%$ in treatment A2 and A3 expressed adverse effects. The highest body weight of chickens of $140.40 \mathrm{~g}$ was recorded in broilers on control treatment A1 with statistically significant differences $(p<0.05)$ compared to treatments A2 (137.32 g) and A3 (135.35 g).

At the end of the second week of test period, a statistically significant $(p<0.05)$ difference in body weight of broiler chickens could be noticed. The highest body weight of $352.68 \mathrm{~g}$ was recorded in control treatment A1, with statistically significant differences compared to other Alternaria spp. treatments. The lowest body weight of chickens was recorded in treatment A3 (335.93 g), while significant differences $(p>0.05)$ between chickens in Alternaria spp. treatments were not recorded (Table 3). The low broiler chicken body weight observed in Alternaria spp. contaminated diet than control could be due to Alternaria spp. toxin tenuazonic acid which was firstly described in 1987 [54].

Table 3. Broiler chickens body weight in the experiment, $\mathrm{g}$.

\begin{tabular}{lccccc}
\hline \multirow{2}{*}{ Age } & \multicolumn{3}{c}{ Treatments in Test } & \multicolumn{2}{c}{ Pooled } \\
\cline { 2 - 6 } & $\mathbf{A 1}$ & $\mathbf{A} 2$ & A3 & SE & $p$ \\
\hline 0 day & $35.52^{\mathrm{a}} \pm 2.82$ & $35.38^{\mathrm{a}} \pm 2.66$ & $34.97^{\mathrm{a}} \pm 2.77$ & 0.16 & 0.098 \\
7 day & $140.40^{\mathrm{a}} \pm 9.61$ & $137.32^{\mathrm{b}} \pm 8.13$ & $135.35^{\mathrm{b}} \pm 8.19$ & 0.47 & 0.000 \\
14 day & $352.68^{\mathrm{a}} \pm 18.44$ & $341.85^{\mathrm{b}} \pm 23.30$ & $335.93^{\mathrm{b}} \pm 22.42$ & 1.29 & 0.000 \\
\hline $\begin{array}{l}\text { Values in the same row marked with the different letters are significantly different at the significance level of } \\
p<0.05 .\end{array}$
\end{tabular}

Numerous researches have registered a broad array of serious wellbeing impacts and medical indications after food animals was subjected to the elevated amount of toxins. Nevertheless, not a lot is seen concerning the wellbeing impacts of toxins at small amounts [55]. Kolawole et al. [55] conducted a long-term feeding trial in order to investigate the impact of small amounts of toxin combinations on the production of poultry fed with naturally contaminated complete feed. Total of eighteen tests with poultry production 
was performed, with closely of 2200 one-day-old Ross-308 birds per each test. As food animals are frequently subjected to low doses of mycotoxin, a cumulative risk evaluation in quantifying and alleviating counter to the economic, welfare, and health influences is necessary for mycotoxins. Hessel-Pras et al. [56] stated that once Alternaria mycotoxins passes the intestinal barrier, they can reach the liver to exert yet uncharacterized molecular effects. Hence, the same group of authors used hepatic in vitro systems to examine selected Alternaria mycotoxins for their induction of metabolism-dependent cytotoxicity, phosphorylation of the histone $\mathrm{H}_{2} \mathrm{AX}$ surrogate marker for DNA double-strand breaks, and relevant marker genes for hepatotoxicity. They have found evidence that $50 \mu \mathrm{mol} / \mathrm{L}$ of $\mathrm{AOH}, \mathrm{AME}, \mathrm{TeA}$, and TEN might be associated with hepatotoxic effects, necrosis, and the development of diseases like cholestasis and phospholipidosis [56]. Kemboi et al. [57] discovered that other developing toxins and metabolites, counting Alternaria, Aspergillus, Fusarium, Penicillium toxins, were discovered at differing concentrations during their research. Such co-occurrences of mycotoxins could trigger synergistic and additive health effects, impeding the food animal production sectors worldwide.

Results of feed consumption and feed conversion ratio are shown in Tables 4 and 5 . Alternaria spp. contaminated wheat grain showed some numerical differences between treatments but without any statistically significant differences in broiler chickens' life stage of life.

Table 4. Feed consumption of broiler chickens, g.

\begin{tabular}{cccccc}
\hline \multirow{2}{*}{ Age } & \multicolumn{3}{c}{ Treatments in Test } & \multicolumn{2}{c}{ Pooled } \\
\cline { 2 - 6 } & A1 & A2 & A3 & SE & $p$ \\
\hline 7 day & $163.57^{\mathrm{a}} \pm 30.51$ & $152.63^{\mathrm{a}} \pm 20.01$ & $162.71^{\mathrm{a}} \pm 29.50$ & 9.62 & 0.564 \\
14 day & $292.33^{\mathrm{a}} \pm 10.16$ & $293.77^{\mathrm{a}} \pm 11.66$ & $284.11^{\mathrm{a}} \pm 17.03$ & 4.72 & 0.689 \\
\hline
\end{tabular}

Values in the same row marked with the different letters are significantly different at the significance level of $p<0.05$.

Table 5. The feed conversion ratio of broiler chickens, $\mathrm{kg} / \mathrm{kg}$.

\begin{tabular}{cccccc}
\hline \multirow{2}{*}{ Age } & \multicolumn{3}{c}{ Treatments in Test } & \multicolumn{2}{c}{ Pooled } \\
\cline { 2 - 6 } & A1 & A2 & A3 & SE & $p$ \\
\hline 7 day & $1.16^{\mathrm{a}} \pm 0.21$ & $1.11^{\mathrm{a}} \pm 0.15$ & $1.21^{\mathrm{a}} \pm 0.22$ & 0.07 & 0.454 \\
14 day & $1.29^{\mathrm{a}} \pm 0.09$ & $1.29^{\mathrm{a}} \pm 0.07$ & $1.33^{\mathrm{a}} \pm 0.08$ & 0.04 & 0.555
\end{tabular}

Values in the same row marked with the different letters are significantly different at the significance level of $p<0.05$.

In addition to wheat, corn is the main feed ingredient used in poultry nutrition. As a wheat grain, the corn can also be naturally infected with mycotoxins, especially with Alternaria spp. Topi et al. [58] have investigated the presence of Alternaria mycotoxins in grains from Albania: alternariol, alternariol monomethyl ether, tenuazonic acid, and tentoxin. They have concluded that the contribution of $\mathrm{AOH}$ and $\mathrm{AME}$ originating from wheat was $0-31.7 \mathrm{ng} / \mathrm{kg}$ body weight per day. In contrast, the contribution of Alternaria toxins through maize consumption was significantly lower.

Changes from optimal internal and external conditions lead to stress from a physiological point of view. Between the main stressors in broiler production, nutritional stressors have a significant role, and within them, the leading role is mycotoxins feed contamination [34].

The highly probable clarification for the remarked results presented in Table 6 is that the pathological modifications strengthen free radical processes by promoting catalytic activities of enzymes engaged in the antioxidative protection, POD, and GR. Still, through the disease phase, lipolysis from the lipid depots could be increased due to reduced feed consumption, which is not the case in our research. Moreover, tiredness of the organism could lead to escalation of free radical processes and higher amounts of lipid peroxides in 
blood. To defend himself, the body initiates its antioxidative safety mechanisms. Decrease of SOD activity was anticipated and is in accordance with other research $[59,60]$.

Table 6. GSH and LPx content and the activity of POD, SOD, GR, and XOD in blood hemolysates, $\mu \mathrm{mol} / \mathrm{g} \mathrm{Hb}$ min.

\begin{tabular}{|c|c|c|c|c|c|c|}
\hline Treatment & GSH & LPx & POD & SOD & GR & XOD \\
\hline A1 & $5.1^{b} \pm 0.9$ & $0.3^{\mathrm{a}} \pm 0.2$ & $65.2^{\mathrm{a}} \pm 4.4$ & $82.6^{\mathrm{a}} \pm 6.1$ & $11.3^{b} \pm 5.9$ & $26.3^{a} \pm 3.6$ \\
\hline $\mathrm{A} 2$ & $5.8^{\mathrm{a}} \pm 0.3$ & $0.3^{\mathrm{a}} \pm 0.1$ & $55.1^{b} \pm 7.2$ & $25.5^{b} \pm 3.5$ & $21.1^{\mathrm{a}} \pm 7.2$ & $27.5^{\mathrm{a}} \pm 2.9$ \\
\hline A3 & $6.2^{\mathrm{a}} \pm 1.1$ & $0.4^{\mathrm{a}} \pm 0.1$ & $59.3^{b} \pm 3.4$ & $29.1^{b} \pm 8.9$ & $19.8^{a} \pm 9.6$ & $26.7^{\mathrm{a}} \pm 4.1$ \\
\hline$p$-value & 0.032 & 0.089 & 0.038 & 0.001 & 0.004 & 0.341 \\
\hline
\end{tabular}

Values in the same row marked with the different letters are significantly different at the significance level of $p<0.05$.

The glutathione has a vital position in reducing the acute toxicity of xenobiotics and products of lipid peroxidation. A statistically significant decrease of POD activity compared to the A1 control treatment was expected since POD catalyzes various proton donors' oxidation with hydrogen peroxide. Having in mind that mycotoxins are classified as hepatotoxins, nephrotoxins, neurotoxins, immunotoxins, and that there are to date, 400 mycotoxins identified and the most critical species producing mycotoxins belong to Aspergillus, Penicillium, Alternaria, and Fusarium genera, Ülger et al. [61] have described their genotoxic effects on the organism. Uric acid increased accumulation, and reduced excretion is closely related to the pathogenesis of gout and hyperuricemia. Higher plants produce different metabolites, which might impede XOD, so disallow the oxidation of hypoxanthine to xanthine then to uric acid in the purine metabolism. Nevertheless, microorganisms generate a group of degrading enzymes, which catalyze uric acid degradation to ammonia. Xanthine oxidoreductase (XOR) has two forms; xanthine oxidase (XOD) and xanthine dehydrogenase $(\mathrm{XDH})$, both of them catalyze the oxidation of hypoxanthine to xanthines, then to uric acid in the purine metabolism [62]. Hafez et al. [63] presented an analysis with the incidence of uric acid in plants and other organisms, especially microorganisms, in addition to the mechanisms by which plant extracts, metabolites, and enzymes could reduce uric acid in the blood. Overactivity of both enzymes (XOD and XDH) cause the accumulation of uric acid in the animal body and form a pathogenesis condition called gout [64]. Additionally, XOD serves as a valuable biological source of oxygen free radicals that participate in various damages of animal tissues leading to many pathological states [65], which could be caused by multiple stress triggers, e.g., mycotoxins [66-68].

Serum biochemical parameters were significantly affected by Alternaria spp. wheat in both treatments compared to control treatment during the starter dietary phase (Table 7). Even though the Alternaria spp. contaminated wheat had no significant effect on growth performance in broiler chicks, it induced the typical clinical signs of hepatic injury, including increased activities of AST and ALT, during the starter dietary period what is in accordance with results of other researchers $[48,69,70]$.

Table 7. Aminotransferase (AST) and alanine aminotransferase (ALT) activity in serum of broiler chickens, U/L.

\begin{tabular}{ccc}
\hline Treatment & AST & ALT \\
\hline A1 & $182.1^{\mathrm{b}} \pm 32.1$ & $1.1^{\mathrm{b}} \pm 0.1$ \\
A2 & $268.8^{\mathrm{a}} \pm 41.3$ & $1.7^{\mathrm{a}} \pm 0.3$ \\
A3 & $271.5^{\mathrm{a}} \pm 33.7$ & $1.6^{\mathrm{a}} \pm 0.2$ \\
-value & 0.075 & 0.039
\end{tabular}

$\overline{\text { Values in the same row marked with the different letters are significantly different at the significance level of }}$ $p<0.05$.

Oxidative stress plays an important role in the development of many animal diseases and it has been shown that have significant implications for the well-being and overall welfare of nonruminants [71]. Various studies have shown that oxidative stress has a funda- 
mental role in the etiopathogenesis of several acute and chronic diseases which are causally related to animal welfare [72]. Over the years oxidative stress has been deeply investigated in human, while in poultry production the data are yet less uneven [73]. Poultry welfare is fundamental in maintaining correct health and a good level of mental and physical well-being of the animal [74]. In our study increased content of total glutathione levels in chicken dietary treatments (5.8 and $6.2 \mu \mathrm{mol} / \mathrm{g} \mathrm{Hb} \mathrm{min}$ ) with addition of blackpoint wheat, indicates that chickens had increased antioxidant defense. These results are directly related with the impaired welfare of chickens. Likewise, certain indicators of impaired welfare of chickens in our expert are increased activity of GR (21.1 and $19.8 \mu \mathrm{mol} / \mathrm{g} \mathrm{Hb} \mathrm{min})$, and decreased activity of SOD (25.5 and $29.1 \mu \mathrm{mol} / \mathrm{g} \mathrm{Hb} \mathrm{min})$, respectively. The similar results were obtained by Brambilla et al. [75] in their research related to influence of oxidative stress markers reactive oxygen metabolites (ROM) and anti-oxidant power (OXY) in swine welfare. Stresses in commercial poultry result from many various factors which negatively impact poultry health, production, and welfare [76]. Oxidative stress is downstream of all these stresses. Oxidative stress in the cells results from an imbalance between free radical production and endogenous antioxidant defense [77]. It is well documented that poultry feed is often contaminated with a wide range of environmental toxicants, bacterial and fungal toxins, and known to affect the health and welfare of poultry [78]. Mycotoxins usually generates reactive oxygen species which induces lipid peroxidation, alters the cellular redox signaling, antioxidant status, and membrane integrity of the cells [79]. Mycotoxins increase cellular apoptosis and affect poultry health, production, and welfare.

\section{Conclusions}

Based on the gained results, it can be concluded that identifying field fungi in all analyzed wheat grain samples showed that the dominant mycotoxigenic fungus was Rhizopus spp., followed by Alternaria spp., and Fusarium spp. Usage of $25 \%$ wheat in complete feed for broiler chickens in the first 14 days of life has shown adverse effects reflected on body weight gain without significant influence on feed consumption and utilization. Concerning oxidative stress, it can be concluded that Alternaria spp. causes high oxidative stress in chickens at a young age negatively influences production and overall broiler chicken's welfare.

Further research on the influence of Alternaria spp. on animal production and genotoxicity is still essential.

Author Contributions: Conceptualization, N.P.; methodology, V.B. and S.T.; software, N.P. and D.M.; validation, M.C., G.V., J.M. and T.S.K.; formal analysis, N.P., V.B., S.T. and G.V.; investigation, N.P.; resources, N.P.; data curation, A.P.; writing-original draft preparation, N.P.; writing-review and editing, V.B. and M.C.; visualization, N.P.; supervision, M.C., S.T., G.V. and T.S.K.; project administration, N.P.; funding acquisition, N.P. and V.B. All authors have read and agreed to the published version of the manuscript.

Funding: This research was funded by the Ministry for Education, Science and Technological Development of the Republic of Serbia.

Institutional Review Board Statement: The study was conducted according to the guidelines of the Declaration of Helsinki and approved by the Ethics Committee of University Business Academy in Novi Sad, EC-2020-321/9, 13.03.2020.

Informed Consent Statement: Not applicable.

Data Availability Statement: Data is contained within the article.

Acknowledgments: This research was supported by the Ministry for Education, Science and Technological Development of the Republic of Serbia within the postdoctoral scholarship in Toxicology and Molecular Genetics under the Grant 451-03-1002/2020-14.

Conflicts of Interest: The authors declare no conflict of interest. 


\section{References}

1. Beloshapka, A.; Buff, P.; Fahey, G.; Swanson, K. Compositional Analysis of Whole Grains, Processed Grains, Grain Co-Products, and Other Carbohydrate Sources with Applicability to Pet Animal Nutrition. Foods 2016, 5, 23. [CrossRef] [PubMed]

2. Fraeyman, S.; Croubels, S.; Devreese, M.; Antonissen, G. Emerging Fusarium and Alternaria Mycotoxins: Occurrence, Toxicity and Toxicokinetics. Toxins 2017, 9, 228. [CrossRef]

3. Thomma, B.P.H.J. Alternaria Spp.: From General Saprophyte to Specific Parasite. Alternaria Mol. Plant Pathol. 2003, 4, 225-236. [CrossRef] [PubMed]

4. Kusaba, M.; Tsuge, T. Phologeny of Alternaria Fungi Known to Produce Host-Specific Toxins on the Basis of Variation in Internal Transcribed Spacers of Ribosomal DNA. Curr. Genet. 1995, 28, 491-498. [CrossRef]

5. Puvača, N.; Bursić, V.; Vuković, G.; Budakov, D.; Petrović, A.; Merkuri, J.; Avantaggiato, G.; Cara, M. Ascomycete Fungi (Alternaria Spp.) Characterization as Major Feed Grains Pathogens. J. Agron. Technol. Eng. Manag. 2020, 3, 499-505.

6. Hillmann, F.; Novohradská, S.; Mattern, D.J.; Forberger, T.; Heinekamp, T.; Westermann, M.; Winckler, T.; Brakhage, A.A. Virulence Determinants of the Human Pathogenic Fungus A Spergillus Fumigatus Protect against Soil Amoeba Predation: Dictyostelium Interactions with Aspergillus Fumigatus. Environ. Microbiol. 2015, 17, 2858-2869. [CrossRef] [PubMed]

7. Ferreira, R.B.; Monteiro, S.; Freitas, R.; Santos, C.N.; Chen, Z.; Batista, L.M.; Duarte, J.; Borges, A.; Teixeira, A.R. Fungal Pathogens: The Battle for Plant Infection. Crit. Rev. Plant Sci. 2006, 25, 505-524. [CrossRef]

8. Jastrzębska, M.; Wachowska, U.; Kostrzewska, M.K. Pathogenic and Non-Pathogenic Fungal Communities in Wheat Grain as Influenced by Recycled Phosphorus Fertilizers: A Case Study. Agriculture 2020, 10, 239. [CrossRef]

9. Müller, M.E.H.; Urban, K.; Köppen, R.; Siegel, D.; Korn, U.; Koch, M. Mycotoxins as Antagonistic or Supporting Agents in the Interaction between Phytopathogenic Fusarium and Alternaria Fungi. World Mycotoxin J. 2015, 8, 311-321. [CrossRef]

10. Li, Q.-Y.; Xu, Q.-Q.; Jiang, Y.-M.; Niu, J.-S.; Xu, K.-G.; He, R.-S. The Correlation between Wheat Black Point and Agronomic Traits in the North China Plain. Crop. Prot. 2019, 119, 17-23. [CrossRef]

11. Lv, G.; Dong, Z.; Wang, Y.; Geng, J.; Li, J.; Lv, X.; Sun, C.; Ren, Y.; Zhang, J.; Chen, F. Identification of Genetic Loci of Black Point in Chinese Common Wheat by Genome-Wide Association Study and Linkage Mapping. Plant Dis. 2020, 104, 2005-2013. [CrossRef]

12. Puvača, N.; Bursić, V.; Petrović, A.; Vuković, G.; Cara, M.; Peulić, T.; Avantaggiato, G. Mycotoxin Incidence of Ochratoxin A in Wine and Methods for Its Control. J. Agron. Technol. Eng. Manag. 2020, 3, 475-482.

13. Čolović, R.; Puvača, N.; Cheli, F.; Avantaggiato, G.; Greco, D.; Đuragić, O.; Kos, J.; Pinotti, L. Decontamination of MycotoxinContaminated Feedstuffs and Compound Feed. Toxins 2019, 11, 617. [CrossRef] [PubMed]

14. Logrieco, A.; Bottalico, A.; Mulé, G.; Moretti, A.; Perrone, G. Epidemiology of toxigenic fungi and their associated mycotoxins for some Mediterranean crops. In Epidemiology of Mycotoxin Producing Fungi: Under the Aegis of COST Action 835 'Agriculturally Important Toxigenic Fungi 1998-2003', EU Project (QLK 1-CT-1998-01380); Xu, X., Bailey, J.A., Cooke, B.M., Eds.; Springer: Dordrecht, The Netherlands, 2003; pp. 645-667. ISBN 978-94-017-1452-5.

15. Somma, S.; Amatulli, M.T.; Masiello, M.; Moretti, A.; Logrieco, A.F. Alternaria Species Associated to Wheat Black Point Identified through a Multilocus Sequence Approach. Int. J. Food Microbiol. 2019, 293, 34-43. [CrossRef]

16. da Cruz Cabral, L.; Terminiello, L.; Fernández Pinto, V.; Fog Nielsen, K.; Patriarca, A. Natural Occurrence of Mycotoxins and Toxigenic Capacity of Alternaria Strains from Mouldy Peppers. Int. J. Food Microbiol. 2016, 236, 155-160. [CrossRef] [PubMed]

17. da Cruz Cabral, L.; Delgado, J.; Patriarca, A.; Rodríguez, A. Differential Response to Synthetic and Natural Antifungals by Alternaria Tenuissima in Wheat Simulating Media: Growth, Mycotoxin Production and Expression of a Gene Related to Cell Wall Integrity. Int. J. Food Microbiol. 2019, 292, 48-55. [CrossRef]

18. Vejdovszky, K.; Sack, M.; Jarolim, K.; Aichinger, G.; Somoza, M.M.; Marko, D. In Vitro Combinatory Effects of the Alternaria Mycotoxins Alternariol and Altertoxin II and Potentially Involved MiRNAs. Toxicol. Lett. 2017, 267, 45-52. [CrossRef]

19. López, P.; Venema, D.; de Rijk, T.; de Kok, A.; Scholten, J.M.; Mol, H.G.J.; de Nijs, M. Occurrence of Alternaria Toxins in Food Products in The Netherlands. Food Control 2016, 60, 196-204. [CrossRef]

20. Nawaz, S.; Scudamore, K.A.; Rainbird, S.C. Mycotoxins in Ingredients of Animal Feeding Stuffs: I. Determination of Alternaria Mycotoxins in Oilseed Rape Meal and Sunflower Seed Meal. Food Addit. Contam. 1997, 14, 249-262. [CrossRef]

21. Escrivá, L.; Oueslati, S.; Font, G.; Manyes, L. Alternaria Mycotoxins in Food and Feed: An Overview. J. Food Qual. 2017, 2017, 1-20. [CrossRef]

22. Puntscher, H.; Aichinger, G.; Grabher, S.; Attakpah, E.; Krüger, F.; Tillmann, K.; Motschnig, T.; Hohenbichler, J.; Braun, D.; Plasenzotti, R.; et al. Bioavailability, Metabolism, and Excretion of a Complex Alternaria Culture Extract versus Altertoxin II: A Comparative Study in Rats. Arch. Toxicol. 2019, 93, 3153-3167. [CrossRef]

23. Ostry, V. Alternaria Mycotoxins: An Overview of Chemical Characterization, Producers, Toxicity, Analysis and Occurrence in Foodstuffs. World Mycotoxin J. 2008, 1, 175-188. [CrossRef]

24. Crudo, F.; Aichinger, G.; Mihajlovic, J.; Dellafiora, L.; Varga, E.; Puntscher, H.; Warth, B.; Dall'Asta, C.; Berry, D.; Marko, D. Gut Microbiota and Undigested Food Constituents Modify Toxin Composition and Suppress the Genotoxicity of a Naturally Occurring Mixture of Alternaria Toxins in Vitro. Arch. Toxicol. 2020, 94, 3541-3552. [CrossRef]

25. Meena, M.; Swapnil, P.; Upadhyay, R.S. Isolation, Characterization and Toxicological Potential of Alternaria-Mycotoxins (TeA, $\mathrm{AOH}$ and AME) in Different Alternaria Species from Various Regions of India. Sci. Rep. 2017, 7, 8777. [CrossRef] [PubMed]

26. Patriarca, A.; Fernández Pinto, V. Prevalence of Mycotoxins in Foods and Decontamination. Curr. Opin. Food Sci. 2017, 14, 50-60. [CrossRef] 
27. Ramires, F.; Masiello, M.; Somma, S.; Villani, A.; Susca, A.; Logrieco, A.; Luz, C.; Meca, G.; Moretti, A. Phylogeny and Mycotoxin Characterization of Alternaria Species Isolated from Wheat Grown in Tuscany, Italy. Toxins 2018, 10, 472. [CrossRef]

28. Gotthardt, M.; Asam, S.; Gunkel, K.; Moghaddam, A.F.; Baumann, E.; Kietz, R.; Rychlik, M. Quantitation of Six Alternaria Toxins in Infant Foods Applying Stable Isotope Labeled Standards. Front. Microbiol. 2019, 10, 109. [CrossRef]

29. Fremy, J.-M.; Alassane-Kpembi, I.; Oswald, I.P.; Cottrill, B.; Van Egmond, H.P. A Review on Combined Effects of Moniliformin and Co-Occurring Fusarium Toxins in Farm Animals. World Mycotoxin J. 2019, 12, 281-291. [CrossRef]

30. Puvača, N.; Bursić, V.; Petrović, A.; Prodanović, R.; Mansour, M.K.; Obućinski, D.; Vuković, G.; Marić, M. Influence of Tea Tree Essential Oil on the Synthesis of Mycotoxins: Ochratoxin A. Maced. J. Anim. Sci. 2019, 9, 25-29.

31. Puvača, N.; Ljubojevic, D.; Živkov Baloš, M.; Đuragić, O.; Bursić, V.; Vuković, G.; Prodanović, R.; Bošković, J. Occurance of Mycotoxins and Mycotoxicosis in Poultry. CDVS 2018, 2, 165-167. [CrossRef]

32. Saleh, K.M.M.; Al-Zghoul, M.B. Effect of Acute Heat Stress on the MRNA Levels of Cytokines in Broiler Chickens Subjected to Embryonic Thermal Manipulation. Animals 2019, 9, 499. [CrossRef] [PubMed]

33. Hasan, R.; Lasker, S.; Hasan, A.; Zerin, F.; Zamila, M.; Chowdhury, F.I.; Nayan, S.I.; Rahman, M.M.; Khan, F.; Subhan, N.; et al. Canagliflozin Attenuates Isoprenaline-Induced Cardiac Oxidative Stress by Stimulating Multiple Antioxidant and AntiInflammatory Signaling Pathways. Sci. Rep. 2020, 10, 14459. [CrossRef] [PubMed]

34. Surai, P.F.; Kochish, I.I.; Fisinin, V.I.; Kidd, M.T. Kidd Antioxidant Defence Systems and Oxidative Stress in Poultry Biology: An Update. Antioxidants 2019, 8, 235. [CrossRef]

35. Abuelo, A.; Hernández, J.; Benedito, J.L.; Castillo, C. Redox Biology in Transition Periods of Dairy Cattle: Role in the Health of Periparturient and Neonatal Animals. Antioxidants 2019, 8, 20. [CrossRef] [PubMed]

36. Preti, R.; Tarola, A.M. Study of Polyphenols, Antioxidant Capacity and Minerals for the Valorisation of Ancient Apple Cultivars from Northeast Italy. Eur. Food Res. Technol. 2020, 247, 273-283. [CrossRef]

37. Surai, P.F.; Kochish, I.I. Antioxidant Systems and Vitagenes in Poultry Biology: Heat Shock Proteins. In Heat Shock Proteins in Veterinary Medicine and Sciences; Heat Shock Proteins; Asea, A.A.A., Kaur, P., Eds.; Springer International Publishing: Cham, Switzerland, 2017; Volume 12, pp. 123-177. ISBN 978-3-319-73376-0.

38. Liguori, I.; Russo, G.; Curcio, F.; Bulli, G.; Aran, L.; Della-Morte, D.; Gargiulo, G.; Testa, G.; Cacciatore, F.; Bonaduce, D.; et al. Oxidative Stress, Aging, and Diseases. Clin. Interv. Aging 2018, 13, 757-772. [CrossRef]

39. Gessner, D.K.; Ringseis, R.; Eder, K. Potential of Plant Polyphenols to Combat Oxidative Stress and Inflammatory Processes in Farm Animals. J. Anim. Physiol. Anim. Nutr. 2017, 101, 605-628. [CrossRef]

40. Kostadinović, L.; Lević, J. Effects of Phytoadditives in Poultry and Pigs Diseases. J. Agron. Technol. Eng. Manag. 2018, 1, 1-7.

41. Layé, S. Polyunsaturated Fatty Acids, Neuroinflammation and Well Being. Prostaglandins Leukot. Essential Fat. Acids (PLEFA) 2010, 82, 295-303. [CrossRef] [PubMed]

42. AOAC. Official Methods of Analysis, 16th ed.; Association of Analytical Communities: Gaithersburg, MD, USA, 1998.

43. Chae, Y.; Hwang, J. Visual Color Difference between Colored-Yarn Mixed Woven Fabrics and Their Instrumentally Measured Colors: The Effects of Individual Yarn Colors and Texture. Fibers Polym. 2020, 21, 792-802. [CrossRef]

44. Pitt, J.I.; Hocking, A.D. Fungi and Food Spoilage; Springer: New York, NY, USA, 2009.

45. Kostadinović, L.M.; Popović, S.J.; Puvača, N.M.; Čabarkapa, I.S.; Kormanjoš, Š.M.; Lević, J.D. Influence of Artemisia Absinthium Essential Oil on Antioxidative System of Broilers Experimentally Infected with Eimeria Oocysts. Vet. Arh. 2016, 86, 253-264.

46. Popović, S.; Puvača, N.; Kostadinović, L.; Džinić, N.; Bošnjak, J.; Vasiljević, M.; Djuragic, O. Effects of Dietary Essential Oils on Productive Performance, Blood Lipid Profile, Enzyme Activity and Immunological Response of Broiler Chickens. Eur. Poult. Sci. 2016, 80, 146. [CrossRef]

47. Puvača, N.; Kostadinović, L.; Popović, S.; Lević, J.; Ljubojević, D.; Tufarelli, V.; Jovanović, R.; Tasić, T.; Ikonić, P.; Lukač, D. Proximate Composition, Cholesterol Concentration and Lipid Oxidation of Meat from Chickens Fed Dietary Spice Addition (Allium Sativum, Piper Nigrum, Capsicum Annuum). Anim. Prod. Sci. 2016, 56, 1920-1927. [CrossRef]

48. Zhang, N.-Y.; Qi, M.; Zhao, L.; Zhu, M.-K.; Guo, J.; Liu, J.; Gu, C.-Q.; Rajput, S.; Krumm, C.; Qi, D.-S.; et al. Curcumin Prevents Aflatoxin B1 Hepatoxicity by Inhibition of Cytochrome P450 Isozymes in Chick Liver. Toxins 2016, 8, 327. [CrossRef]

49. Funnell, D.L.; Pedersen, J.F. Association of Plant Color and Pericarp Color with Colonization of Grain by Members of Fusarium and Alternaria in Near-Isogenic Sorghum Lines. Plant Dis. 2006, 90, 411-418. [CrossRef]

50. Janic-Hajnal, E.; Belovic, M.; Plavsic, D.; Mastilovic, J.; Bagi, F.; Budakov, D.; Kos, J. Visual, Instrumental, Mycological and Mycotoxicological Characterization of Wheat Inoculated with and Protected against Alternaria Spp. Hem. Ind. 2016, 70, 257-264. [CrossRef]

51. Xu, W.; Han, X.; Li, F.; Zhang, L. Natural Occurrence of Alternaria Toxins in the 2015 Wheat from Anhui Province, China. Toxins 2016, 8, 308. [CrossRef] [PubMed]

52. Li, F.; Yoshizawa, T. Alternaria Mycotoxins in Weathered Wheat from China. J. Agric. Food Chem. 2000, 48, 2920-2924. [CrossRef] [PubMed]

53. Kosiak, B.; Torp, M.; Skjerve, E.; Andersen, B. Alternaria and Fusarium in Norwegian Grains of Reduced Quality-A Matched Pair Sample Study. Int. J. Food Microbiol. 2004, 93, 51-62. [CrossRef]

54. Giambrone, J.J.; Davis, N.D.; Diener, U.L. Effect of Tenuazonic Acid on Young Chickens. Poult. Sci. 1978, 57, 1554-1558. [CrossRef] 
55. Kolawole, O.; Graham, A.; Donaldson, C.; Owens, B.; Abia, W.A.; Meneely, J.; Alcorn, M.J.; Connolly, L.; Elliott, C.T. Low Doses of Mycotoxin Mixtures below EU Regulatory Limits Can Negatively Affect the Performance of Broiler Chickens: A Longitudinal Study. Toxins 2020, 12, 433. [CrossRef]

56. Hessel-Pras, S.; Kieshauer, J.; Roenn, G.; Luckert, C.; Braeuning, A.; Lampen, A. In Vitro Characterization of Hepatic Toxicity of Alternaria Toxins. Mycotoxin Res. 2019, 35, 157-168. [CrossRef]

57. Kemboi, D.C.; Ochieng, P.E.; Antonissen, G.; Croubels, S.; Scippo, M.-L.; Okoth, S.; Kangethe, E.K.; Faas, J.; Doupovec, B.; Lindahl, J.F.; et al. Multi-Mycotoxin Occurrence in Dairy Cattle and Poultry Feeds and Feed Ingredients from Machakos Town, Kenya. Toxins 2020, 12, 762. [CrossRef]

58. Topi, D.; Tavčar-Kalcher, G.; Pavšič-Vrtač, K.; Babič, J.; Jakovac-Strajn, B. Alternaria Mycotoxins in Grains from Albania: Alternariol, Alternariol Monomethyl Ether, Tenuazonic Acid and Tentoxin. World Mycotoxin J. 2019, 12, 89-99. [CrossRef]

59. Kustrzeba-Wójcicka, I.; Siwak, E.; Terlecki, G.; Wolańczyk-Mędrala, A.; Mędrala, W. Alternaria Alternata and Its Allergens: A Comprehensive Review. Clin. Rev. Allerg. Immunol. 2014, 47, 354-365. [CrossRef] [PubMed]

60. AlMatar, M.; Var, I.; Koksal, F. How Does Alternaria Alternata-Derived Alternariol Affect Our Health? Mini Rev. Org. Chem. 2016, 13, 465-472. [CrossRef]

61. Ülger, T.G.; Uçar, A.; Çakıroğlu, F.P.; Yilmaz, S. Genotoxic Effects of Mycotoxins. Toxicon 2020, 185, 104-113. [CrossRef] [PubMed]

62. Unno, T.; Sugimoto, A.; Kakuda, T. Xanthine Oxidase Inhibitors from the Leaves of Lagerstroemia Speciosa (L.) Pers. J. Ethnopharmacol. 2004, 93, 391-395. [CrossRef]

63. Hafez, R.M.; Abdel-Rahman, T.M.; Naguib, R.M. Uric Acid in Plants and Microorganisms: Biological Applications and GeneticsA Review. J. Adv. Res. 2017, 8, 475-486. [CrossRef]

64. Lioté, F. Hyperuricemia and Gout. Curr. Rheumatol. Rep. 2003, 5, 227-234. [CrossRef]

65. Alsultanee, I.R.; Ewadh, M.J.; Mohammed, M.F. Novel Natural Anti Gout Medication Extract from Momordica Charantia. J. Nat. Sci. Res. 2014, 4, 16-23.

66. Hou, Y.-J.; Zhao, Y.-Y.; Xiong, B.; Cui, X.-S.; Kim, N.-H.; Xu, Y.-X.; Sun, S.-C. Mycotoxin-Containing Diet Causes Oxidative Stress in the Mouse. PLoS ONE 2013, 8, e60374. [CrossRef]

67. Richard, J.L. Some Major Mycotoxins and Their Mycotoxicoses-An Overview. Int. J. Food Microbiol. 2007, 119, 3-10. [CrossRef] [PubMed]

68. Doi, K.; Uetsuka, K. Mechanisms of Mycotoxin-Induced Neurotoxicity through Oxidative Stress-Associated Pathways. Int. J. Mol. Sci. 2011, 12, 5213-5237. [CrossRef] [PubMed]

69. Sun, L.-H.; Zhang, N.-Y.; Sun, R.-R.; Gao, X.; Gu, C.; Krumm, C.S.; Qi, D.-S. A Novel Strain of Cellulosimicrobium Funkei Can Biologically Detoxify Aflatoxin B1 in Ducklings. Microb. Biotechnol. 2015, 8, 490-498. [CrossRef]

70. Klein, P.J.; Van Vleet, T.R.; Hall, J.O.; Coulombe, R.A., Jr. Biochemical Factors Underlying the Age-Related Sensitivity of Turkeys to Aflatoxin B1. Comp. Biochem. Physiol. Part C Toxicol. Pharmacol. 2002, 132, 193-201. [CrossRef]

71. Molinari, L.; Basini, G.; Ramoni, R.; Bussolati, S.; Aldigeri, R.; Grolli, S.; Bertini, S.; Quintavalla, F. Evaluation of Oxidative Stress Parameters in Healthy Saddle Horses in Relation to Housing Conditions, Presence of Stereotypies, Age, Sex and Breed. Processes 2020, 8, 1670. [CrossRef]

72. Reiser, S.; Wuertz, S.; Schroeder, J.P.; Kloas, W.; Hanel, R. Risks of Seawater Ozonation in Recirculation Aquaculture-Effects of Oxidative Stress on Animal Welfare of Juvenile Turbot (Psetta Maxima, L.). Aquat. Toxicol. 2011, 105, 508-517. [CrossRef]

73. Altan, Ö.; Pabuçcuoğlu, A.; Altan, A.; Konyalioğlu, S.; Bayraktar, H. Effect of Heat Stress on Oxidative Stress, Lipid Peroxidation and Some Stress Parameters in Broilers. Br. Poult. Sci. 2003, 44, 545-550. [CrossRef] [PubMed]

74. Carenzi, C.; Verga, M. Animal Welfare: Review of the Scientific Concept and Definition. Ital. J. Anim. Sci. 2009, 8, 21-30. [CrossRef]

75. Brambilla, G.; Civitareale, C.; Ballerini, A.; Fiori, M.; Amadori, M.; Archetti, L.I.; Regini, M.; Betti, M. Response to Oxidative Stress as a Welfare Parameter in Swine. Redox Rep. 2002, 7, 159-163. [CrossRef]

76. Wasti, S.; Sah, N.; Mishra, B. Impact of Heat Stress on Poultry Health and Performances, and Potential Mitigation Strategies. Animals 2020, 10, 1266. [CrossRef] [PubMed]

77. Shankar, K.; Mehendale, H.M. Oxidative Stress. In Encyclopedia of Toxicology; Elsevier: Amsterdam, The Netherlands, 2014; pp. 735-737, ISBN 978-0-12-386455-0.

78. Murugesan, G.R.; Ledoux, D.R.; Naehrer, K.; Berthiller, F.; Applegate, T.J.; Grenier, B.; Phillips, T.D.; Schatzmayr, G. Prevalence and Effects of Mycotoxins on Poultry Health and Performance, and Recent Development in Mycotoxin Counteracting Strategies. Poult. Sci. 2015, 94, 1298-1315. [CrossRef] [PubMed]

79. Mishra, B.; Jha, R. Oxidative Stress in the Poultry Gut: Potential Challenges and Interventions. Front. Vet. Sci 2019, 6, 60. [CrossRef] [PubMed] 